\title{
A CERTEZA FULCRAL DE WITTGENSTEIN
}

\author{
Danièle Moyal-Sharrock \\ Universit Hertfordshire \\ Janyne Sattler (Tradução) \\ Universidade Federal de Santa Maria
}

\begin{abstract}
... as perguntas que fazemos e as nossas dúvidas apoiam-e em certas proposições que são excluídas da dúvida, como dobradiças sobre as quais aquelas se movem. (DC 341) ${ }^{1}$
\end{abstract}

\begin{abstract}
RESUMO: O desenvolvimento do presente texto parte do pressuposto inicial segundo o qual grande parte do Da Certeza é dedicada a expor a distinção entre 'certeza' e 'conhecimento'. Nossas certezas básicas - ou 'fulcrais' ou, ainda, 'dobradiças' [hinges] - formam a nossa imagem de mundo e sustentam o nosso conhecimento, não sendo elas mesmas, porém, de natureza epistêmica. As deliberações de Wittgenstein levamno a compreender que as nossas certezas básicas compartilham as seguintes características conceituais; elas são todas: não epistêmicas, indubitáveis, não empíricas, gramaticais, não proposicionais, inefáveis, exibidas na ação [enacted] e fundacionais. Estas características necessárias das certezas fulcrais são investigadas com algum detalhe ao longo do texto que se segue.
\end{abstract}

ABSTRACT: This paper works on the assumption that much of On Certainty is devoted to fleshing out the distinction between certainty and knowledge. Our basic certainties or 'hinge certainties', or 'hinges' - make up our world picture and underpin knowledge, not being themselves, however, of an epistemic nature. Wittgenstein's deliberations in On Certainty show him to realize that our basic certainties share the following conceptual features; they are all: nonepistemic, indubitable, nonempirical, grammatical, nonpropositional, ineffable, enacted and foundational. The necessary features of hinges are discussed at some length in the text to follow.

Se a última obra de Wittgenstein foi postumamente intitulada Da Certeza, é porque a certeza é o tema principal da obra. Em sua tentativa de compreender a natureza da nossa confiança [assurance] a mais básica - a nossa confiança a respeito de coisas tais como 'Eu estou

\footnotetext{
${ }^{1}$ N. da T.: Exceto no caso de algumas citações indicadas abaixo, os parágrafos do Da Certeza seguem aqui a tradução para o português tal como estabelecida pela edição bilingue das Edições 70: Wittgenstein, L. Da Certeza. Introdução de Sérgio Miranda. Trad. de Maria Elisa Costa, Lisboa: Edições 70, 2012, (DC).
}

(C) Dissertatio - Volume Suplementar, Junho - 2015 
aqui', 'Eu tenho um corpo', 'A Terra já existia muito antes de eu nascer', 'Eu sou um ser humano', 'Há muitos outros seres humanos', 'Aqui está uma mão'2 - Wittgenstein emprega e considera várias outras expressões para além do termo 'certeza', mas o que ele exclui desde o princípio é que esta confiança seja um conhecimento: 'Se tu sabes que aqui está uma mão, nós te concedemos tudo o mais' (DC 1). Claro, ele não deixa as coisas por isso mesmo; grande parte do Da Certeza é dedicada a expor a distinção entre certeza e conhecimento.

Dizer que nossas certezas básicas (ou 'certezas fulcrais', ou 'dobradiças', como vamos também chamá-las a partir da metáfora expressa no parágrafo DC 341) ${ }^{3}$ sustentam o conhecimento não significa dizer que o conhecimento é tudo o que elas sustentam. Como escreve Wittgenstein: elas 'pertencem ao fundamento de todo o operar com o pensamento (com a linguagem)' (DC 401; ênfase minha), dos nossos jogos de linguagem (DC 403) - o que significa dizer que elas são a base tanto das nossas crenças falsas quanto das nossas crenças verdadeiras justificadas. Nossas certezas básicas formam a nossa imagem de mundo, à qual Wittgenstein se refere como uma 'mitologia' (DC 95), não no sentido de que ela é uma imagem mistificadora, mas no sentido de que ela é uma imagem que não está fundamentada na ciência (conhecimento).

\footnotetext{
${ }^{2}$ As observações que compõem o Da Certeza foram inspiradas pelas discussões mantidas com Norman Malcolm em 1949 a propósito dos textos 'Prova de um mundo exterior' (1939) e 'Uma defesa do senso comum' (1925) de G.E. Moore. Estes sete exemplos de certezas básicas são extraídos destes dois textos, mas Wittgenstein se vale ainda de outros tipos de exemplo, tais como: 'Eu chamo-me...' (DC 571); 'Eu venho desta ou daquela cidade' (OC 67); 'Eu nunca estive na lua' (DC 111); 'Minha mãos não desaparecem quando não lhes presto atenção' (DC 153).

${ }^{3}$ N. da T.: 'Hinge', como adjetivação de 'certeza' ou de 'proposição', é um termo correntemente traduzido como 'fulcral' - e esta é também a tradução aqui mantida para todas as ocorrências de 'hinge certainty'; no entanto, Moyal-Sharrock se vale do termo enquanto substantivo, e sua argumentação nos permite traduzi-lo como 'dobradiça' (ou invés de fulcro, como poderia também ser o caso); muitas das referências da autora às crenças e certezas básicas aparecem, portanto, apenas sob a designação geral de 'dobradiças'.
} 


\section{Certeza fulcral vs. Conhecimento}

Pois eu gostaria de responder a Moore 'Tu não sabes de nada!' quando ele diz 'Eu sei que isto...' (DC 407)

Ao tentar descrever uma certeza que ele não pode provar e que, no entanto, lhe parece ser a mais indubitável de todas, G.E. Moore a ela se refere como 'conhecimento', porque este é para ele o conceito que expressa o maior grau de convicção em nosso continuum epistêmico. Wittgenstein concorda com o fato de que estes objetos da confiança de Moore correspondem àqueles das nossas crenças as mais inquestionáveis, mas discorda de que a certeza em questão seja de natureza epistêmica; ele acredita que esta confiança é, na verdade, de um tipo mais fundacional do que o conhecimento:

Quando digo 'como sei isso?', não quero dizer que duvido disso. Eis aqui um fundamento de todo o meu agir. Mas parece-me que ela é falsamente exprimida por 'Eu sei...' (DC $414){ }^{4}$

Por que Wittgenstein não toma esta certeza como sendo um conhecimento? Simplesmente porque ele adere à visão padrão do conhecimento como crença verdadeira justificada:

Costuma-se dizer 'Eu sei...' quando se está disposto a oferecer razões conclusivas. 'Eu sei' diz respeito a uma possibilidade de provar a verdade. (DC 243).

Se Moore disser saber que a Terra existe, etc., a maioria de nós concordará com ele em que ela existiu durante todo esse tempo, e também acreditará nele quanto ao facto de ele estar convencido disso. Mas ele também tem a razão correta para a sua convicção? Porque, caso não tenha, ele certamente não sabe. (DC 91).

A nossa certeza de que a Terra existe não pode ser dita como sendo justificada, porque ela nunca foi verificada: 'Mas não tenho a minha

\footnotetext{
${ }^{4}$ N. da T.: A edição portuguesa traduz 'Grundlage' por 'base', o que não é, claro, equivocado; no entanto, como ficará claro posteriormente, 'fundamento' ou 'fundação' parece ser uma tradução mais condizente para este parágrafo.
} 
imagem de mundo porque me certifiquei da sua correção; também não é porque dela estou convencido' (DC 94). Na verdade, diferentemente dos objetos do nosso conhecimento, nós provavelmente nunca sequer pensamos, mesmo que efemeramente, a respeito dos objetos da nossa certeza fulcral:

Acredito que tive bisavós, que as pessoas que se diziam meus pais eram realmente os meus pais, etc. Essa crença pode jamais ter sido proferida e o pensamento de que é assim jamais ter sido pensado. (DC 159).

E mesmo que tenhamos alguma vez pensado tal pensamento, não foi isto o que de fato ocasionou ou confirmou a nossa confiança. $\mathrm{O}$ fato de que temos pais é algo simplesmente 'admitido como uma obviedade, nunca colocado em causa e mesmo jamais formulado'(DC 87). Claro, nós podemos formular a nossa certeza a respeito destes truísmos, e isto é o que Moore faz, mas ele confunde tais formulações com asserções epistêmicas. Este é o ponto em que Wittgenstein o corrige. Ele o repreende por confundir o conhecimento com uma convicção de qualidade não-epistêmica que lhe é logicamente subjacente, procedendo a um corte categorial entre eles: "“Conhecimento" e "certeza" pertencem a categorias diferentes' (DC 308) ${ }^{5}$, escreve ele.

O problema de muitas das interpretações do Da Certeza e, em geral, da natureza das crenças básicas, é a sua insistência em ver aquela certeza subjacente ao nosso conhecimento como sendo ela mesma um conhecimento. Como Michael Williams o coloca: 'O conhecimento ... emerge de conhecimento prévio' (2001, 176). E embora Williams reconheça um pano de fundo predefinido e um componente pragmático neste pano de fundo, em sua visão, nossas 'certezas basilares' são inevitavelmente proposicionais. Afinal, pergunta-se Williams, como é que as nossas crenças básicas poderiam não ser proposicionais, se são elas que devem gerar as nossas crenças não básicas:

\footnotetext{
${ }^{5}$ N. da T.: Na tradução das Edições 70 (2012), lê-se, na verdade: "Saber" e "segurança" pertencem a categorias diferentes'. O contexto da discussão de Moyal-Sharrock não nos autoriza, no entanto, a manter estes termos: "Knowledge" and "certainty" belong to different categories', na tradução em inglês; lemos 'Wissen' e 'Sicherheit', respectivamente, no original em alemão.
} 
Independentemente do modo como o conhecimento básico é compreendido, ele deve ser capaz de estabelecer relações lógicas com quaisquer juízos que dele dependam. Por exemplo, ele deve ser capaz de ser consistente ou inconsistente com eles. Mas isso significa dizer que até mesmo o conhecimento básico deve envolver um conteúdo proposicional... $(2001,97)$.

No entanto, a mensagem do Da Certeza é precisamente a de que o conhecimento não tem de estar na base do conhecimento. Para Wittgenstein, o conhecimento subjacente não é constituído por proposições justificadas previamente, passíveis de justificação explícita sob demanda, mas, como veremos, por certezas não proposicionais certezas 'em ação' - as quais podem ser verbalmente proferidas para fins heurísticos e cuja análise conceitual revela a sua função de regra injustificável da gramática. De modo que nossas crenças básicas estão para nossas crenças não básicas, não como as crenças proposicionais estão para outras crenças proposicionais, mas como as regras da gramática estão para as crenças proposicionais. Daí a ausência e inutilidade da inferência e da proposicionalidade. $\mathrm{O}$ conhecimento não precisa emergir do conhecimento: 'Porque é que o jogo de linguagem deve assentar num conhecimento?'(DC 477) ${ }^{6}$, pergunta Wittgenstein.

A natureza não epistêmica das certezas fulcrais é averiguada pela ausência lógica de justificação e de verificação no que se refere à confiança que nelas depositamos. Este ponto será melhor desenvolvido em nossa investigação acerca das outras características que são compartilhadas pelas dobradiças as quais igualmente impedem a sua consideração em termos de afirmações de conhecimento.

\section{As características necessárias das dobradiças}

As deliberações de Wittgenstein no Da Certeza levam-no a compreender que as nossas certezas básicas compartilham as seguintes características conceituais; elas são todas.

\footnotetext{
${ }^{6}$ N. da T.: Novamente, aqui, optamos por 'conhecimento' em detrimento de 'saber' como aparece na tradução portuguesa; o termo usado pela autora é 'Knowledge'.
} 
(1) não epistêmicas. elas não são cognoscíveis [known]

(2) indubitáveis: dúvida e erro são logicamente sem sentido no que lhes diz respeito

(3) não empíricas: elas não são conclusões derivadas da experiência

(4) gramaticais. elas são regras da gramática

(5) não proposicionais: elas não são proposições

(6) inefáveis. elas são, qua certezas, inefáveis

(7) exibidas na ação [enacted] $]^{7}$ : elas podem apenas ser mostradas naquilo que dizemos e fazemos

(8) fundacionais: elas são o fundamento infundado do pensamento e da ação

Tendo já discutido a primeira característica, volto-me agora para as demais.

\subsection{Indubitabilidade: dúvida e erro são logicamente sem sentido}

Há casos em que a dúvida é despropositada, mas há casos em que ela parece ser logicamente impossível. (DC 454)

Nossas certezas básicas não são objetos de convicção subjetiva ou psicológica, mas de uma convicção lógica: 'Não posso duvidar dessa proposição sem abrir mão de todo o julgar' (DC 494; ênfase minha). Mesmo Descartes pensava deste modo: '...E como poderia eu negar que estas mãos e este corpo sejam meus? A não ser, talvez, que eu me compare a esses insensatos ${ }^{9}(1641,12) .{ }^{9}$ A dúvida equivale aqui à perda dos limites de sentido: 'Se alguém me dissesse que duvida de ter um corpo, eu o tomaria por um tolo' (DC 257).

Também não é possível equivocar-se acerca de uma certeza fulcral: se eu acredito estar sentada em meu quarto quando eu não o estou, ou que meus pais sejam lobos, não é o fato de que eu possivelmente esteja equivocada que estaria sob investigação, mas

\footnotetext{
${ }^{7}$ N. da T.: Poderíamos traduzir 'enacted' como, literalmente, 'encenadas', mas a reflexão de Moyal-Sharrock aproxima as certezas básicas de um sentido de mostrabilidade que não pode ser confundido com uma "mera encenação" (teatral, por exemplo).

${ }^{8}$ Mantendo ao mesmo tempo, porém, que estas crenças são derivadas dos sentidos $(1641,13)$. Wittgenstein argumenta que elas não o são (ver seção 2.3).

${ }^{9}$ N. da T.: A citação em questão respeita a tradução para o português tal como dada pela edição de 1973 pela Abril Cultural: Descartes, R., Meditações. São Paulo: Abril Cultural, 1973, p.94.
} 
minha habilidade de compreender as palavras que estou usando (i.e. meu conhecimento de inglês) ou, mais tristemente, minha sanidade. Um equívoco resulta de negligência, fadiga ou ignorância; nós não podemos dizer de alguém que acredita que gatos crescem em árvores ou que o mundo não existe, que ele está 'equivocado':

O ser humano não pode errar em certas circunstâncias. (Aqui, 'pode' é usado no sentido lógico e a proposição não diz que nessas circunstâncias o ser humano não pode dizer algo falso.) Se Moore declarasse o contrário daquelas proposições que ele toma por certas, não só não compartilharíamos a sua opinião, mas também o tomaríamos por mentalmente perturbado. (DC 155)

Fechando assim a porta logicamente à dúvida e ao erro no que se refere às nossas certezas básicas, Wittgenstein fecha a porta ao tipo de contextualismo ou de biperspectivismo neo-humeano o qual Michael Williams lhe atribui. ${ }^{10} \mathrm{Na}$ leitura de Williams, Wittgenstein acredita que a dúvida cética não tenha qualquer influência sobre a atmosfera pragmática da vida ordinária, mas que seja uma manifestação de dúvida legítima e séria no contexto da reflexão filosófica. Mas Williams está errado. Para Wittgenstein, o gênio maligno cartesiano nunca é uma ameaça plausível; ele não possui mais força no estudo filosófico do que o possui em nossa vida ordinária. Não pode haver, para Wittgenstein, contexto algum no qual nossas certezas fulcrais possam ser postas em dúvida ou justificadas, já que a sua indubitabilidade é conceitual, e não contextual. Não se trata de uma dobradiça que pode ser posta em dúvida em alguns contextos e não em outros; mas uma dobradiça nunca pode ser posta em dúvida, enquanto o Doppelgänger de uma dobradiça o pode. O Doppelgänger de uma dobradiça é uma sentença que parece idêntica ou similar àquela que expressa uma dobradiça, mas que é usada em um contexto no qual ela funciona como uma proposição empírica ou epistêmica. Por exemplo, a sentença: 'Há outros seres humanos além de mim' pode ser uma proposição

\footnotetext{
10 'Parece... que o caminho wittgensteiniano trilhado junto do cético tende a seguir em direção de um biperspectivismo humeano' $(1991,26)$. Williams toma Wittgenstein como identificando 'a característica absolutamente crucial da dúvida filosófica' como aquela que envolve 'levar a sério a possibilidade de que objetos físicos não existam' $(2004,85)$.
} 
descritiva (e portanto aberta à dúvida) quando endereçada a um marciano em um filme de ficção científica; ao passo que qua dobradiça, ela nunca pode ser posta em dúvida - seja no estudo filosófico ou não. O problema de Williams é que ele pensa que a dobradiça ela mesma pode, em alguns contextos, ser posta em dúvida.

$\mathrm{O}$ que pode ter dado a Williams a impressão de que Wittgenstein adere ao contextualismo, é a diferença que ele marca, no Da Certeza, entre o uso de "eu sei..." tal como feito na vida ordinária e seu uso no discurso filosófico:

O que viso reside igualmente na diferença entre a constatação casual 'Eu sei que isso...', tal como ela é utilizada no dia a dia, e essa exteriorização feita pelo filósofo. (DC 406)

Mas Wittgenstein sugere tratarmos diferentemente estas afirmações de conhecimento, não por pensar que nós sabemos nossas certezas básicas na vida ordinária e não no estudo filosófico, mas pelo fato de Moore ser um filósofo obrigá-lo a usar 'eu sei...' com precisão técnica; ou seja, exclusivamente em casos de crença verdadeira justificada; ${ }^{11}$ isto, no entanto, não pode ser exigido da pessoa comum: nós não podemos e não devemos esperar que ela use 'eu sei...' somente quando é 'crença verdadeira justificada' aquilo que ela quer dizer com isso. É característico de Wittgenstein que ele se recuse a reprovar ou a corrigir o uso ordinário da linguagem, mas o filósofo deve poder ser responsabilizado:

Pois eu gostaria de responder a Moore 'Tu não sabes de nada!' quando ele diz 'Eu sei que isso...'. Mas não responderia isso a alguém que, sem intenção filosófica, fala desse modo. (DC 407; ênfase original)

E assim, de acordo com Wittgenstein, um não filósofo poderia dizer: 'eu sei...' em casos nos quais um filósofo não o pode, mas isso não significa que a pessoa comum sabe onde o filósofo não sabe.

Não é o caso, como o afirma Williams, de que as dúvidas céticas sejam dúvidas antinaturais $(1991,2)$, mantidas apenas sob as condições

\footnotetext{
${ }^{11}$ A não ser que Moore indicasse preferir afastar-se da definição filosófica padrão de conhecimento, algo precisamente que ele intenta não fazer.
} 
artificiais ou não naturais da reflexão especificamente filosófica, mas antes de que elas não sejam dúvidas em absoluto. Williams parece não ter notado que no Da Certeza Wittgenstein elucida o conceito de dúvida de duas maneiras: ele mostra que a dúvida universal é impossível e que nem tudo aquilo que possui a aparência de dúvida é dúvida:

\begin{abstract}
Se alguém dissesse duvidar da existência das suas mãos, as examinasse continuamente por todos os lados, procurasse convencer-se de que não é alguma miragem ou algo parecido, então ficaríamos inseguros se deveríamos chamar a isso duvidar. Poderíamos descrever o seu modo de agir como sendo o comportamento da dúvida, mas o seu jogo não seria o nosso. (DC 255) 12
\end{abstract}

Em alguns casos, o que parece ser dúvida é somente comportamento de dúvida. Claro, onde a dúvida não possui motivação racional ou justificação, ela pode ter causas (patológicas) (DC 74), mas a dúvida normal deve ter razóes. Não é suficiente dizer ou imaginar que duvidamos: a dúvida genuína, como a suspeita, deve ter fundamentos (DC 322, 458). Se Williams considera a dúvida cética possível, é porque, equivocadamente - tal como Moore e a maioria dos filósofos desde Descartes, - ele toma a mera articulação da dúvida pela dúvida: ${ }^{13}$ 'Faz-se uma falsa imagem da dúvidá, adverte Wittgenstein (DC 249).

A dúvida universal de Descartes é mero comportamento de dúvida, um mero balbucio de dúvida dependente das próprias certezas que rejeita. Hume dá um passo em direção à lucidez ao admitir que a dúvida cética não se sustenta na vida ordinária; mas é preciso Wittgenstein para reconhecer que a dúvida universal não se sustenta em

\footnotetext{
${ }^{12} \mathrm{~N}$. da T.: O trecho final deste parágrafo lê-se da seguinte forma na versão portuguesa: 'Poderíamos descrever o seu modo de agir como um que é semelhante àquele de duvidar, mas o seu jogo não seria o nosso.' - Moyal-Sharrock enfatiza aqui, justamente, no entanto, a expressão 'the behaviour of doubt' ou 'doubt-behaviour', com o que parece adequar-se melhor a expressão 'comportamento de dúvida'.

${ }^{13}$ Claro, nossas certezas fulcrais são passíveis de exame filosófico (de fato, é nisto em que estão engajados o Da Certeza e o presente artigo), mas examinar não é duvidar. Aliás, nem mesmo a consideração científica de nossas dobradiças significa colocá-las em dúvida: eu posso imaginar nunca envelhecer; e até mesmo engajar-me na busca por uma poção para a juventude eterna, mas isso não significa que eu esteja colocando em questão a dobradiça 'humanos envelhecem'; na verdade, todo meu esforço decorre do fato de que para mim ela permanece firme.
} 
absoluto, dentro ou fora do estudo - e isto, não por razões pragmáticas, mas conceituais: 'Uma dúvida que duvidasse de tudo não seria uma dúvida' (DC 450); 'Quem quisesse duvidar de tudo, também não chegaria a duvidar. O próprio jogo da dúvida já pressupõe a certeza' (DC 115). Wittgenstein desmistificou a dúvida cética; ele mostrou que o cético está apenas sob uma ilusão de dúvida (DC 19).

A certeza básica, tal como retratada por Wittgenstein e tal como ela opera em nossa vida, não pode ser subsumida sob o 'conhecimento', porque ela nada tem a ver com verdade ou justificação. Dizer que as dobradiças são logicamente indubitáveis não é dizer que elas sejam necessariamente verdadeiras. Não há questão de verdade ou de falsidade no fundamento: 'Se o verdadeiro é o fundamentado, então o fundamento não é verdadeiro, nem falso' (DC 205). ${ }^{14}$ A indubitabilidade das nossas dobradiças não resulta de as termos confirmado, mas decorre do fato de que elas não são passíveis em absoluto de confirmação ou de falsificação: 'Eu sei como verificar que eu tenho duas moedas em meu bolso. Mas eu não posso verificar que eu tenho duas mãos, porque eu não o posso duvidar' (LWI 832). As dobradiças são logicamente impermeáveis à dúvida. Em algum ponto, justificação e dúvida perdem o seu sentido; ali onde a pá entorta está o fundamento infundado onde a 'justificação tem um fim’ (DC 192).

\subsection{Não empíricas: dobradiças não são conclusões derivadas da experiência}

A dificuldade é reconhecer a não-fundamentação da nossa crença. (DC 166)

Se nossas certezas fulcrais não são logradas por justificação ou raciocínio [reasoning], elas igualmente não resultam da indução. Nas Investigações Filosóficas Wittgenstein pergunta:

'A certeza de que o fogo me queimará baseia-se na indução.' Isto significa que concluo que 'eu sempre me queimei na chama e portanto isto também acontecerá agora'? Ou a

\footnotetext{
${ }^{14}$ N. Da T.: Lê-se em alemão 'Grund', que Moyal-Sharrock emprega como 'ground', mas que a tradução portuguesa expressa como 'razão'.
} 
experiência anterior é a causa da minha certeza, e não seu fundamento? (IF 325). ${ }^{15}$

E no Da Certeza ele responde:

O esquilo não infere por indução que vai precisar de armazenar comida também no próximo inverno. E tampouco precisamos de uma lei da indução para justificar as nossas ações e previsões. (DC 87)

Claro, é de fato o caso que muitos fenômenos naturais sejam realmente confiáveis - p.ex., que os seres humanos nascem e morrem, que montanhas não brotam do chão em um única dia. Segundo uma leitura empírica, nossas certezas básicas são conclusões racionais às quais chegamos (tacitamente ou não) a partir da observação de tais regularidades. Wittgenstein se opõe a isso: 'Não, a experiência não é a razão para o nosso jogo de julgar. E também não é o seu êxito notável' (DC 131). Mas dizer que as nossas certezas não são fundamentadas (ou seja: justificadas) pela regularidade da experiência e seu sucesso recorrente, não significa excluir todo e qualquer impacto da experiência sobre a nossa certeza. Experiência e sucesso recorrentes contribuem efetivamente para a nossa certeza, mas o fazem de forma não inferencial e não indutiva; ou seja, através de condicionamento ${ }^{16}$, não de raciocínio. Isto é o que Wittgenstein quer dizer quando ele fala da experiência como uma causa e não como um fundamento: 'Este jogo dá bons resultados. Isso pode ser a causa dele ser jogado, mas não é a razão’ (DC 474).

Isto é também o que Wittgenstein chama de realismo sem empirismo ${ }^{17}$. A experiência (aquilo que ele entende por 'realismo') está sempre aí, mas é apenas em nossos momentos epistêmicos e científicos que a empregamos como um fundamento ou uma razão ('empirismo')

\footnotetext{
${ }^{15}$ N. da T.: Wittgenstein, L. Investigações Filosóficas. Trad. José Carlos Bruni. São Paulo: Editora Nova Cultural, 1999, (IF); a expressão final, 'e não seu fundamento' [ 'nicht ihr Grund'], não consta dessa tradução.

16 'Sim, não é óbvio que a possibilidade de um jogo de linguagem [i.e. gramática] é condicionada por certos factos?' (DC 617). O condicionamento inclui treinamento e exposição repetida; para uma abordagem mais completa sobre o modo como os fatos condicionam a gramática, ver Moyal-Sharrock (2013a).

17 'Não o empirismo e, no entanto, um realismo em filosofia, isto é o mais difícil' (RFM VI, 23).
} 
para as nossas ações e crenças. Nós pensamos chegar à certeza de que 'bebês não matam' da mesma maneira como chegamos a uma conclusão pelo raciocínio. Esta confusão se deve à nossa constante suposição de que algum raciocínio, inferência, racionalização ou justificação ocorreu onde, na verdade, não houve nada. Wittgenstein deixa claro que, muito embora façamos apelo a um raciocínio implícito no intuito de explicar os nossos atos e crenças mais básicos, na realidade, um tal raciocínio nunca ocorre: não chegamos 'à convicção conscientemente por certas vias de pensamento' (DC 103; 84). Nossa certeza aqui não é racional, mas animal: 'É como quando me sirvo imediatamente de algo' (DC 510; ênfase minha). Tais sequências de palavras como 'eu tenho um corpo' ou 'seres humanos precisam de oxigênio' ou 'bebês não podem cuidar de si mesmos', embora se pareçam com conclusões empíricas, são na verdade expressões de coisas que tomamos, ou que viemos a tomar (através de treinamento e exposição repetida), como permanecendo indubitavelmente firmes para nós. ${ }^{18}$

A certeza fulcral não é resultado de julgamento; o conhecimento o é. O conhecimento é racionalmente fundamentado na realidade, na natureza, na experiência: 'Se sei algo, isso depende de a evidência me dar razão ou me contradizer. Pois dizer que uma pessoa sabe que tem dores não significa nada' (DC 504). E assim como é sem sentido [nonsensical] dizer 'eu sei que estou dor' como se eu o tivesse deduzido a partir da observação, pela mesma razão é sem sentido dizer 'eu sei que existo' ou 'eu sei que objetos externos existem'.

Que nossas dobradiças não possam ser o resultado de verificação não significa dizer que algumas delas (e.g., 'eu sou uma mulher') não podem ser verificadas e confirmadas por outra pessoa além de nós mesmos; é simplesmente o caso de que a nossa própria certeza não está fundamentada sobre qualquer raciocínio ou verificação, sejam eles nossos ou de outra pessoa:

Que sou um homem e não uma mulher, pode ser verificado, mas se eu dissesse que sou uma mulher, e quisesse explicar o

\footnotetext{
${ }^{18}$ Estes são, algumas vezes, fatos - por exemplo: 'Eu estou aqui', mas nem sempre; por exemplo: 'A Terra é plana' era, antes de 1492, uma certeza que pertencia à Weltbild da maioria das pessoas.
} 
erro dizendo que não havia testado a declaração, ninguém admitiria a explicação. (DC 79)

A nossa certeza quanto ao fato de que os seres humanos precisam de nutrição é tão lógica e não racionalizada quanto ' $2+2=4$ '. É uma certeza que não é justificada pela realidade, mas que é subjacente a tudo aquilo que podemos dizer ou questionar acerca da realidade. Para que nossas palavras e atos façam sentido, devemos tomar como pontos de partida regularidades tais como 'os seres humanos precisam de nutrição'; o que Wittgenstein compreendeu, é que tais pontos de partida não são empíricos, mas lógicos (ou gramaticais).

\subsection{Gramaticais: dobradiças são regras da gramática}

Algumas passagens no Da Certeza assinalam uma peculiaridade das certezas de tipo mooreano [Moore-type] (e.g., 'Existe no presente um corpo humano vivo, que é o meu corpo', 'Esse corpo nasceu num determinado momento no passado', 'Tive...muitas experiências diferentes' $(1925,33))$ : elas se assemelham a proposições empíricas, mas o que elas expressam é indubitável, não-hipotético. $\mathrm{Na}$ verdade, podemos delas dizer o que dizemos das sentenças matemáticas: 'Disputai outras coisas; isso é firme, é uma dobradiça sobre a qual a vossa disputa pode girar' (DC 655). Estar certo significa, aqui, estar inabalavelmente e, contudo, não cognitivamente situado sobre algo que nos permite pensar, falar ou agir significativamente. Este algo é a gramática.

Wittgenstein se pergunta se as certezas de tipo mooreano poderiam ser uma espécie de híbrido ${ }^{19}$, mas esta possibilidade não é julgada aceitável: não que regra e proposição empírica venham a fundirse uma na outra (DC 309), mas que aquilo que parece ser uma proposição empírica nem sempre o é. Aqui, novamente, como é comum em nossas especulações filosóficas, somos enganados pela forma:

\footnotetext{
${ }^{19}$ No Da Certeza, nenhuma menção é feita a 'proposições sintéticas a priori'.
} 
Ou seja, interessa-nos que não possa haver dúvida sobre certas proposições empíricas, se um juízo deve ser realmente possível. Ou ainda: fico propenso a acreditar que nem tudo o que tem a forma de uma proposição empírica é uma proposição empírica. (DC 308)

Quero dizer: proposições com a forma de proposições empíricas e não só proposições da lógica pertencem ao fundamento de todo o operar com o pensamento (com a linguagem). (DC 401)

Wittgenstein compreendeu que proposições de tipo mooreano, muito embora possuam a forma de proposições empíricas, são na verdade regras da gramática:

Poder-se-ia então dar razão a Moore se ele fosse interpretado assim: uma proposição dizendo que ali está um objeto físico pode ter uma função lógica semelhante a uma dizendo que ali está uma mancha vermelha. (DC 53)

Quando Moore diz saber isto e aquilo, ele não enumera mais que proposições empíricas que afirmamos sem um teste especial, ou seja, proposições que desempenham um papel lógico peculiar no sistema das nossas proposições empíricas. (DC 136)

Quer dizer, um papel ou status gramatical. ${ }^{20} \mathrm{E}$ na medida em que nossas certezas básicas são regras, elas não podem em absoluto ser proposições, sejam elas empíricas ou não.

\subsection{Não-proposicionalidade: dobradiças não são proposições}

Wittgenstein nunca deixou de considerar a proposicionalidade como logicamente vinculada à verdade e à falsidade: para que seja uma

\footnotetext{
${ }^{20}$ Todas as certezas básicas funcionam como regras gramaticais, mas nem todas as regras gramaticais são certezas básicas: uma das características das certezas básicas é a de que elas se manifestam como maneiras impensadas de agir, ao passo que não possuímos uma compreensão automática ou impensada de muitas das regras matemáticas e gramaticais; algumas delas requerem pensamento, cálculo ou memorização (p.ex. '235+532=767'; 'um funâmbulo é um equilibrista').
} 
proposição, uma sentença deve ser passível de verdade ou falsidade. ${ }^{21} \mathrm{E}$ na medida em que uma regra não é nem verdadeira nem falsa, ${ }^{22}$ regras não são proposições. As certezas fulcrais sendo regras gramaticais e, portanto, não sendo nem verdadeiras nem falsas - 'o fundamento não é verdadeiro, nem falso’ (DC 205) - também não são proposições. Há uma passagem no $D a$ Certeza que não deixa dúvidas quanto à nãoproposicionalidade das nossas certezas fundamentais: 'e não encontramos o fim quando certas proposições nos são dadas imediatamente como verdadeiras' (DC 204). No entanto, há outras passagens que se referem às nossas crenças fundamentais como 'proposições'. A inconsistência se deve parcialmente ${ }^{23}$ à tradução ('Satz' em alemão significa tanto 'sentença' quanto 'proposição'); e parcialmente ao fato de que a não-proposicionalidade das dobradiças não é algo que já esteja imediatamente claro para Wittgenstein no $D a$ Certeza, com o que, por força de hábito filosófico e em referência às proposições mooreanas e de tipo mooreano, ele chama estas certezas de 'proposições'.

De todos os insights aos quais chega Wittgenstein no Da Certeza, que crenças básicas sejam maneiras de agir (e não proposições que nos são dadas imediatamente como verdadeiras) é o insight o mais revolucionário deles, e deve, portanto, ter sido o mais difícil de alcançar e desenvolver. No entanto, ele o alcança de fato:

Mas a fundamentação, a justificação por meio de evidência, tem um fim; - e não encontramos o fim quando certas proposições nos são dadas imediatamente como verdadeiras, ou seja, ele não é um tipo de ver da nossa parte, mas é, antes, o nosso agir que se encontra na base do jogo de linguagem. (DC 204)

\footnotetext{
${ }^{21} \mathrm{Eu}$ argumento alhures que, para Wittgenstein, uma proposição é essencialmente bipolar - o que significa dizer que ela deve ser passível de verdade $e$ falsidade (ver Moyal-Sharrock 2007, 35-39), no entanto, a bivalência é aqui suficiente para o meu argumento.

22 "Podemos traçar a distinção entre hipótese e regra gramatical por meio das palavras "verdadeiro" ou "falso", por um lado, e "prático" e "não-prático", por outro. As palavras "prático" e "não-prático" caracterizam regras. Uma regra não é verdadeira ou falsa.' (AWL 70)

${ }^{23}$ Para uma explicação mais completa e detalhada, ver Moyal-Sharrock (2007).
} 
Isso o ajuda a compreender que as dobradiças são logicamente inefáveis; elas não podem ser ditas significativamente; mas podem, qua certezas, apenas mostrar-se.

\subsection{Inefabilidade: dobradiças são logicamente inefáveis}

Portanto, parece-me que eu já sabia algo durante todo o tempo e, contudo, não faz sentido dizer tal coisa, não faz sentido proferir essa verdade. (DC 466)

Tentar articular uma certeza não resulta em manifestação de certeza, mas em uma manifestação de contrassenso [nonsense]. ${ }^{24}$ Isto é porque uma regra gramatical é sem sentido ${ }^{25}$ (ela não tem sentido; ela determina o sentido), e tentar articulá-la no jogo de linguagem simplesmente solidifica o jogo. Algo que é percebido como esquisito (DC 553); incompreensível (DC 347); uma piada (DC 463); um sinal de loucura (DC 467).

Proferir uma dobradiça no fluxo do discurso ordinário é proferir um contrassenso; é proferir uma regra onde nenhuma lembrança de uma regra é necessária. Para usar um exemplo do Da Certeza: se um silvicultor dissesse aos seus homens: 'Esta árvore tem de ser cortada, e mais esta e esta', esta seria então uma afirmação informativa. Mas se em seguida ele dissesse, apontando para uma árvore perfeitamente ordinária: 'Isto é uma árvore', seus homens o olhariam com perplexidade. O jogo de linguagem é subitamente congelado; tal manifestação do silvicultor não faz nenhum sentido: ele parece querer

\footnotetext{
${ }^{24}$ N. da T.: O termo 'nonsensical' foi acima traduzido como 'sem sentido', assim como o serão outras ocorrências qualificativas de 'nonsense'; no entanto, o contexto e a estruturação desta passagem parecem exigir uma substantivação, onde 'contrassenso' parece ser a melhor opção contra o 'absurdo' e suas implicações de interpretação resoluta.

${ }^{25}$ Lembre-se de que para Wittgenstein o contrassenso não é unicamente uma violação de sentido; 'a negação do contrassenso é um contrassenso' [ 'the negation of nonsense is nonsense'] (CL 2.7.1927). Em sua visão, 'Esta vara tem um comprimento' é tão sem-sentido quanto 'Esta vara não tem comprimento'. A última é sem sentido pelo fato de que infringe uma regra da gramática, e a primeira pelo fato de que expressa uma regra da gramática: '... quando ouvimos as duas proposições, "Esta vara tem um comprimento" e sua negação "Esta vara não tem comprimento", nós tomamos partido e favorizamos a primeira sentença, ao invés de declarar a ambas como um contrassenso [Unsinn]' (PG 129; ênfase minha).
} 
informar seus homens de algo tão básico que eles teriam aprendido quando crianças. Que isto é uma árvore é uma regra da gramática; uma dobradiça que, enquanto tal, está 'firme... e fora de circulação' (DC 210) - ou seja, ela possibilita, mas não pertence ao jogo de linguagem. Dizer [to say] uma dobradiça no fluxo do jogo de linguagem, invariavelmente detém o jogo; a fluidez do jogo depende de que suas dobradiças permaneçam invisíveis (não ditas): tudo o que o silvicultor precisa dizer para que seus homens comecem a trabalhar, é quais árvores que precisam ser cortadas. A nossa certeza compartilhada de que 'isto é uma árvore' pode tão somente ser mostrada em nossas operações normais relativas à árvore; ela não pode, qua certeza, ser dita significativamente.

Proferir uma certeza básica no interior do jogo de linguagem invariavelmente detém o jogo. ${ }^{26}$ Dizer que as certezas fulcrais são inefáveis não significa meramente apontar para a superfluidade de se articular o óbvio; ${ }^{27}$ significa enfatizar sua indizibilidade lógica. Afinal, mesmo que em circunstâncias heurísticas nós possamos formular a gramática (p.ex., ao ensinarmos a linguagem a uma criança, nós dizemos: 'Isto é uma árvore', e apontamos para o carvalho ao seu lado), tal formulação no fluxo do jogo de linguagem apenas detém o jogo.

Para Wittgenstein, a dizibilidade está internamente vinculada ao sentido e ao uso:

Assim como "Eu estou aqui" só tem sentido em certos contextos, mas não quando digo isso a alguém que está sentado à minha frente e me vê claramente - não porque isso

\footnotetext{
${ }^{26}$ No entanto, embora as regras sejam sempre desprovidas de sentido, quando elas são formuladas em circunstâncias heurísticas nas quais a expressão da regra se faz necessária, ela então não causa perplexidade e não detém os procedimentos. Expressões heurísticas encontramse fora do jogo de linguagem; elas são preparatórias ao jogo (MWL 72; BT 38; PI 26, 49). A formulação de uma certeza fulcral nunca é uma ocorrência de certeza, mas, na melhor das hipóteses, a expressão de uma regra.

${ }^{27}$ Poderíamos ser tentados a pensar que a inefabilidade das certezas fulcrais no jogo de linguagem, faz delas meras implicaturas griceanas, aquelas 'coisas bizarras que nós "não deveríamos dizer" [mas as quais] seriam, apesar de tudo, verdadeiras', como o coloca Charles Travis $(1997,95)$. Mas é precisamente esta referência à verdade - como também a ligação conceitual da implicatura com a intencionalidade, o conhecimento e a inferência - que impossibilita qualquer aproximação não trivial entre elas e as dobradiças. Além disso, as implicaturas não funcionam como regras da gramáticas.
} 
fosse supérfluo, mas porque o seu sentido não seria determinado pela situação, carecendo, pois, de uma determinação dessas. (DC 348; a primeira ênfase é minha).

Em certos contextos, as palavras 'Eu estou aqui' são dizíveis (por exemplo, quando eu entro em casa e, para informar ao meu marido de que eu acabei de chegar, eu digo: 'Eu estou aqui'; ou quando se diz 'Isto é uma árvore' no contexto de duas pessoas que estão discutindo sobre se algo é um arbusto ou uma árvore). Mas em contextos nos quais as mesmas sentenças não servem nem para informar, nem para expressar ou descrever, elas são inúteis e, portanto, desprovidas de sentido: elas nada dizem. ${ }^{28}$

A certeza básica é um tipo de confiança animal, não proposicional e inarticulada em certas coisas: 'Quero considerar aqui o ser humano como animal: como um ser primitivo, ao qual se atribui instinto, mas não raciocínio' (DC 475). Moore e Wittgenstein articularam ambos algumas de nossas certezas. Isto é heuristicamente ou filosoficamente importante na medida em que nos permite individualizar e elucidar os objetos da nossa certeza básica, mas é algo que também pode ser enganador: pois pode nos dar a impressão de que nossas crenças básicas são proposicionais, epistêmicas e intelectuais. Devemos nos lembrar de que a formulação e a elucidação da nossa certeza animal não a torna uma certeza intelectual ou proposicional. ${ }^{29}$ Nossa certeza básica é inteiramente animal. Podemos verbalizá-la, mas a verbalização de uma certeza básica nunca é uma ocorrência de certeza básica. Ela manifesta-se exclusivamente na ação. Ela é uma lógica em ação.

\footnotetext{
${ }^{28}$ Parece ser contra-intuitivo pensar em sentenças tais como 'Eu estou aqui' ou 'Eu sei que isso é uma árvore' como sendo inefáveis. A chave aqui é não confundir 'inefável' ou 'indizível' (em sentido técnico wittgensteiniano) com inexprimível [unutterable] ou não-vocalizável, e lembrar que estas sentenças não são inefáveis em todos os seus usos. Como já foi observado, sentenças idênticas podem ter usos diferentes e, portanto, diferentes status. Não é porque uma certa combinação de palavras é dizível e falsificável em um contexto ou uso, que ela é dizível e falsificável em outro.

${ }^{29}$ Ademais, as dobradiças não perdem o seu caráter de contrassenso em um estudo qualquer: elas são sem sentido porque são gramaticais. A investigação filosófica das dobradiças é uma investigação das regras da gramática, e não de afirmações que podem ser submetidas à dúvida.
} 


\subsection{Exibidas na ação: as dobradiças podem apenas ser mostradas naquilo que dizemos e fazemos}

Aquilo que os filósofos tradicionalmente chamaram de 'crenças básicas ou tácitas' não podem, sob pena de regresso ao infinito, ser elas mesmas crenças proposicionais, e a concepção wittgensteiniana de certeza fulcral ${ }^{30}$ mostra, de maneira inédita, que elas de fato não o são. Enquanto os epistemólogos sempre pensaram em nossas crenças básicas como proposições, Wittgenstein as vê como regras da gramática ou como limites de sentido, que se manifestam como maneiras de agir. Eu ajo na certeza de estar sentada aqui, de estar em Londres, de falar inglês, de o mundo existir e de a Terra ser redonda. Como observa von Wright: '... os fragmentos de uma imagem de mundo subjacentes aos usos da linguagem não são, originalmente e estritamente, de forma alguma proposições. O conhecimento prévio não é um conhecimento proposicional. Mas se este fundamento não é proposicional, o que então ele e? Talvez pudéssemos dizer que ele é uma praxis' $(1982,178)$.

A certeza fulcral é uma certeza exibida na ação, que se mostra na regularidade do nosso funcionamento normal, básico, no mundo. A nossa certeza fulcral de que alguma coisa é uma árvore se mostra no fato de que a tratamos como algo que serve para lenha, ou para sentarmos sob sua sombra, ou que examinamos para sua classificação. Dobradiças são regras gramaticais, cuja única manifestação se dá com aquilo que fazemos e naquilo que dizemos: ${ }^{31}$

Ou seja, pertence à lógica das nossas investigações científicas que certas coisas não sejam em ato colocadas em dúvida. (DC $342)^{32}$

\footnotetext{
${ }^{30}$ Em uma célebre metáfora, Wittgenstein usa a imagem das dobradiças que devem permanecer firmes a fim de que a porta da investigação possa girar (DC 341; 343).

31 "No sentido de Moore, "Eu sei que isto é uma mão" não quer dizer o mesmo ou algo semelhante a "Em jogos de linguagem nos quais não há dúvida quanto à existência desta mão, eu poderia fazer declarações como "Tenho dores nesta mão" ou "Esta mão é mais fraca do que a outra" ou "Uma vez quebrei esta mão", etc.?' (DC 371).

${ }^{32}$ N. da T.: A diferença da tradução é aqui crucial. Na edição portuguesa lê-se: 'Ou seja, pertence à lógica das nossas investigações científicas que certas coisas não sejam de facto colocadas em dúvida'. A expressão em questão aqui, no original alemão, é 'in der Tat'.
} 
Em ato [in der Tat], certas coisas não são postas em dúvida. A lógica está inserida em nossas práticas - em nossos atos. 'A criança não aprende que há livros, que há poltronas, etc., etc., mas sim aprende a ir buscar livros, sentar-se em poltronas, etc.' (DC 476; ênfase minha). Nossa vida, nossos atos, nos mostram que nós não duvidamos e não podemos duvidar de algumas coisas ao procedermos de fato à dúvida e ao conhecimento.

A conclusão de Wittgenstein no Da Certeza é a de que nossa certeza básica é lógica, logicamente inefável, e exibida na ação. Como ele já o havia suspeitado em Remarks on the Foundations of Mathematics. 'Os limites do empirismo não são suposições sem garantia ou intuitivamente sabidas como corretas; eles são maneiras pelas quais... nós agimos' (RFM VII, 21). Com isso, aquilo que eu gostaria de chamar de enativismo [enactivism] de Wittgenstein, impacta de alguma forma a epistemologia. ${ }^{33}$

\subsection{Fundacionais: as dobradiças são o fundamento infundado do pensamento e da ação}

Não pode haver qualquer equívoco quanto ao fundacionismo de Wittgenstein no Da Certeza; isto é algo que está aí explicitamente declarado - 'Eis aqui um fundamento de todo o meu agir' (DC 414); 'Na base da crença fundamentada está a crença não fundamentada' (DC $253)^{34}$ - e repetidamente ilustrado: nossas certezas básicas são vistas como o 'substrato de todas as [nossas] pesquisas e afirmações' (DC 162), como 'a armação de todas as nossas considerações' (DC 211) ou como as 'dobradiças' sobre as quais nossas dúvidas e questões podem girar (DC 341). ${ }^{35}$

\footnotetext{
${ }^{33}$ Como o fez a filosofia da mente e a filosofia da linguagem (ver Moyal-Sharrock (2013b)).

${ }^{34}$ N. da T.: 'Base' lê-se 'foundation' na citação em inglês e 'Grund' no original em alemão.

${ }^{35}$ Avrum Stroll (2004) contou mais de 70 entradas nas quais Wittgenstein se vale de uma linguagem explicitamente fundacional, além de muitas outras passagens contendo locuções menos explícitas do mesmo impulso.
} 
Apesar da abundância de imagens e observações comprobatórias, muitos epistemólogos negam a presença de um fundacionismo no $D a$ Certeza. ${ }^{36}$ Michael Williams o faz ao argumentar que as certezas fulcrais não preenchem as condições necessárias para um fundacionismo, e que o 'fundacionismo' de Wittgenstein não corresponde a uma teoria do conhecimento em qualquer sentido semelhante ao tradicional (2005, 51-2). No entanto, (embora eu não tenha tempo de expô-lo aqui), as certezas fulcrais na verdade preenchem as condições dadas por Williams para um fundacionismo, ${ }^{37} \mathrm{e}$ podem ser vistas (não obstante o desgosto de Wittgenstein pela teoria) como correspondendo a uma teoria do conhecimento e das crenças básicas.

$\mathrm{O}$ fundacionismo de Wittgenstein diverge do fundacionismo tradicional na medida em que interpreta a base como diferindo daquilo que sustenta. Nossa certeza não é um rio corrente, mas o leito de rocha que permite ao rio fluir; não uma construção, mas a armação que torna a construção possível; as dobradiças sobre as quais uma porta pode girar. Nós não conhecemos [know] as nossas crenças fundacionais. Como é, então, que elas são capazes de sustentar alguma coisa? Gramaticalmente, como vimos. Há uma diferença categorial, e não uma diferença de grau, entre as regras subjacentes ao pensamento e o pensamento. A natureza revolucionária do retrato dado por Wittgenstein acerca das crenças básicas é precisamente a sua diferença relativamente às nossas outras crenças, e elas assim o fazem porque são não proposicionais, não epistêmicas, ${ }^{38} \mathrm{e}$ gramaticais. Isto é uma modificação do fundacionismo, não a sua ausência.

\footnotetext{
${ }^{36}$ Ver Williams (2005); outros comentadores que o negaram foram Wright $(1985,469)$, Phillips (1988, xv, 40, 54, 89; 2001, 182). Quanto às posições pró-fundacionistas, ver Stroll (1994), Conway (1989), Mounce (2005).

37 Williams afirma que os fundamentos tradicionais possuem quatro características: universalidade, especificidade, independência (ou autonomia) e adequação (conexão lógica), e que Wittgenstein despoja as certezas humanas de todas as quatro $(2005,51)$. Williams está equivocado em todos pontos. Neste texto, eu exponho as características necessárias das dobradiças (especificidade); e a sua natureza (lógica) gramatical [seção 2.4] lhes dá a sua independência ou autonomia (para Wittgenstein, a gramática é autônoma) assim como a sua adequação lógica. Quanto à sua universalidade, a seção 3 provê uma taxonomia que inclui dobradiças universais. Isto é mais amplamente discutido em Moyal-Sharrock (2007).

${ }^{38} \mathrm{Ou}$ seja, nossas crenças básicas não são nem proposicionais nem cognoscíveis; para colocá-lo brevemente: elas não são crenças verdadeiras justificadas-que, mas crenças não proposicionaisem. Ver Moyal-Sharrock (2007), capítulo 9.
} 


\section{Uma fundação estriada: uma taxonomia das dobradiças}

Todas as nossas certezas fulcrais compartilham certas características, as quais nós acabamos de examinar. Mas nem todas as compartilham da mesma maneira. As dobradiças são todas fundacionais, mas algumas o são universalmente, outras apenas localmente. Todas as nossas certezas são infundadas, mas algumas o são porque são instintivas, outras porque a sua aquisição é alcançada através de treinamento ou exposição repetida. Mas seja qual for a sua origem - quer tenham sido ou não inculcadas como regras da gramática - todas as nossas dobradiças funcionam como regras da gramática: elas condicionam o sentido. Em sendo regras, elas não podem ser falsificadas, mas algumas podem ser abandonadas, tornar-se obsoletas $^{39}$, enquanto outras não o podem (sua rejeição 'pareceria levar tudo consigo e mergulhar num caos' (DC 613)). De tal forma que, não obstante a sua natureza conceitual uniforme, o fundamento é estratificado. Eu produzi uma taxonomia das dobradiças. Ela não é do próprio Wittgenstein, mas almeja apenas colocar em uma apresentação mais manejável e mais perspícua os variegados exemplos de dobradiças usados no Da Certeza: ${ }^{40}$

1) Dobradiças linguísticas: p. ex.: ' $2+2=4$ ', 'Como se chama a cor do sangue humano', 'O que se chama "uma laje” / "um pilar”, 'Que cor significa a palavra 'azul'”, 'Esta cor se chama azul / verde (em português)', 'As palavras que compõem esta sentença são do português', 'A é um objeto físico' (DC 455, $340,565,545,126,624,158,36)$.

2) Dobradiças pessoais: p. ex.: 'Há muitos meses que moro no endereço $E$ ', 'Eu agora estou sentado numa poltrona', 'Eu estou na Inglaterra', 'Eu nunca estive na Bulgária / Ásia Menor', 'Eu nunca estive na Lua', 'Acabei de almoçar', 'A

\footnotetext{
${ }^{39}$ Como o considera Dan Hutto relativamente àquilo que ele chama de 'atitudes intencionais puras' ou sem conteúdo, 'não há uma maneira direta de se alterar atitudes intencionais puras através de expedientes racionais diretos, tais como argumento ou persuasão retórica. Se a crença de um indivíduo é uma atitude intencional pura, ela não tem conteúdo. Ela não estabelecerá, portanto, relações lógicas padrão e estará, assim, aberta à uma revisão por meios racionais' (2013, 169). As certezas fulcrais podem ser caracterizadas como crenças-em, ou atitudes intencionais puras (embora nem todas destas últimas sejam certezas fulcrais).

${ }^{40} \mathrm{Eu}$ contei aproximadamente 300 ocorrências de 'dobradiças' em aproximadamente 200 das 676 passagens que constituem o Da Certeza.
} 
pessoa que está à minha frente é o meu velho amigo Fulano' (DC 70, 552-3, 421, 269, 419, 111, 659, 613).

3) Dobradiças locais: p. ex.: 'Existe uma ilha, a Austrália', 'Nunca ninguém esteve na Lua', 'Não é possível chegar até a Lua', 'A Terra é redonda', 'Os trens normalmente chegam em uma estação de trem' (DC 159, 106, 106, 291, 339).

4) Dobradiças universais: p. ex.: 'A Terra existe', 'Há objetos físicos', 'As coisas não desaparecem sistematicamente quando nós não estamos olhando', 'Uma pessoa que teve a cabeça decepada está morta e jamais viverá novamente,' 'As árvores não se transformam gradualmente em seres humanos e seres humanos em árvores', 'Eu tenho um cérebro', 'Eu sou um ser humano', 'Eu tenho antepassados' (DC 209, 35-6, 234, 274, 513, 159, 4, 234).

O status gramatical do primeiro subconjunto é óbvio; elas são o que Wittgenstein chama, antes do Da Certeza e depois do Tractatus, de regras gramaticais. Elas não são em si mesmas um objeto de análise no Da Certeza, mas são mencionadas como um referencial contra o qual é medida a natureza lógica ou gramatical mais problemática dos outros três tipos de dobradiça. ${ }^{41}$ As certezas que compõem o segundo grupo têm a ver com nossas vidas individuais; aquelas do terceiro grupo pertencem, ou pertenceram, à imagem de mundo de uma comunidade de pessoas em um dado momento: (p. ex., 'A Terra é plana', 'A Terra é redonda'; 'Seres humanos não podem ir à Lua'; 'Seres humanos podem ir à Lua'). Algumas destas dobradiças (p. ex., 'Seres humanos podem ir à Lua') possuem uma origem empírica, mas não é com o status de proposição empírica que elas chegam a se fundir no fundamento. ${ }^{42}$ Outras dobradiças (p. ex., 'Seres humanos não podem ir à Lua') já foram por sua vez desalojadas da fundação (enquanto regras que se tornaram obsoletas). No entanto, nem todas as dobradiças são passíveis de expulsão; é impossível deslocar dos fundamentos do pensamento dobradiças tais como 'Seres humanos estiveram na Lua' ou ' $\mathrm{O}$ mundo

\footnotetext{
${ }^{41}$ Ver, p. ex., DC 448 e 657.

${ }^{42}$ Para uma discussão acerca dos processos pelos quais algumas de nossas dobradiças tornam-se 'fixas' (e, inversamente, 'desarticuladas' ['unhinged'], ver Moyal-Sharrock (2007), 104-116; 137-47. Wittgenstein fala de condicionamento, endurecimento, fossilização e fusão ('Este fato está fundido no fundamento do nosso jogo de linguagem' (DC 558 - [N. da T.: tradução modificada; o verbo 'giessen' pode ser aqui traduzido como 'fundir' ao invés de 'integrar', como o quer a tradução portuguesa.]), deixando claro que a entrada e a exclusão da fundação não se realiza por raciocínio, falsificação ou verificação.
} 
já existe há muito tempo’. O quarto conjunto compõe-se de dobradiças universais. certezas que são fundacionais para todos os seres humanos normais.

As dobradiças dos últimos três conjuntos talvez não pareçam ser os candidatos mais plausíveis ao papel de regra gramatical, mas devemos recordar que o seu status não é determinado pela aparência, mas pelo uso, e que para Wittgenstein: 'O que pertence à gramática são todas as condições necessárias (o método) ... para a compreensão (do sentido)' (PG, p.88). Todas as nossas certezas fulcrais fazem parte deste 'método':

Fico propenso a dizer: Moore não sabe o que afirma saber, mas o que ele afirma saber é firme para ele, assim como o é para mim; considerar isso como firme pertence ao método do nosso duvidar e investigar. (DC 151)

\section{Conclusão}

Longe de desvalorizar o conhecimento, Wittgenstein reafirma o seu papel diante da multiplicidade de nossas seguranças, mas também faz aí alguns ajustes. $\mathrm{Na}$ posição última tradicionalmente mantida pelo conhecimento, Wittgenstein coloca a certeza. Uma certeza que é tanto animal quanto lógica. Com isso, ele quer dizer que a sua indubitabilidade, embora essencial à nossa compreensão de sentido, não é alcançada racionalmente, e pode manifestar-se apenas como uma maneira de agir. Por ser essencial à nossa compreensão de sentido (DC 24, 220), esta certeza sustenta todas as questões e dúvidas, incluindo a dúvida universal do cético, que é assim invalidada. Se não estivesse apoiado na certeza, o cético não poderia sequer formular a sua dúvida (DC 369-70): no 'fundamento de todo o operar com o pensamento (com a linguagem)' (DC 401), está uma certeza que nenhum pensamento ou questão pode comprometer; uma certeza cuja natureza animal e não racional torna-a impermeável à dúvida racional. 
Para mim, enquanto pessoa razoável, não pode haver dúvida a esse respeito. - Isso é assim mesmo. - (DC 219)

Uma pessoa razoável não tem certas dúvidas. (DC 220)

Aqui, o cético poderia então reivindicar uma vitória parcial diante da afirmação de Wittgenstein de que nós não sabemos que nunca estivemos na estratosfera, ou que objetos externos existem, ou que não somos cérebros em cubas; mas a vitória mais radical está do lado da certeza: 'Ou seja, pertence à lógica das nossas investigações científicas que certas coisas não sejam em ato colocadas em dúvida. (DC 342). Há aqui, portanto, sustentando logicamente a própria formulação da dúvida cética, uma certeza sine qua non.

O Da Certeza nos mostra que Wittgenstein resolveu o problema que se propôs a resolver - aquele que ocupou a Moore e que infestou a epistemologia, - o problema do fundamento do conhecimento. O insight revolucionário de Wittgenstein no Da Certeza concerne a ideia de que aquilo que os filósofos tradicionalmente chamaram de 'crenças básicas' - aquelas crenças sobre as quais todo o conhecimento deve, em última instância, estar fundamentado - não pode, sob pena de regresso ao infinito, estar ulteriormente fundamentado sobre crenças proposicionais. Ele chega assim a compreender que as crenças básicas são, na verdade, maneiras irrefletidas ou animais de agir, as quais, uma vez formuladas (por filósofos, por exemplo), se parecem com proposições (empíricas). É esta aparência enganosa que leva os filósofos a acreditar que no fundamento do pensamento reside também ainda um pensamento. No entanto, embora elas possam frequentemente parecer conclusões empíricas, nossas certezas básicas constituem a sustentação infundada, não proposicional, do conhecimento, e não o seu objeto. Situando assim o fundamento do conhecimento sobre certezas não reflexivas, as quais se manifestam como maneiras de agir, Wittgenstein encontrou o lugar onde a justificação chega a um fim, e resolveu o problema do regresso das crenças básicas - e, de passagem, mostrou a impossibilidade lógica do ceticismo hiperbólico. Eu creio que esta seja uma conquista realmente revolucionária para a filosofia o Da Certeza tornando-se digno do título de 'terceira obra-prima' de Wittgenstein. 


\section{Referências}

CONWAY, G. (1989) Wittgenstein on Foundations. New Jersey: Humanities Press.

DESCARTES, R. (1641) Meditations on First Philosophy, trans. and ed. J. Cottingham, revised ed. (Cambridge: Cambridge University Press, 1996).

HUTTO, D. D. (2013) 'Why believe in contentless beliefs?' in N. Nottelmann (ed.), New Essays on Belief: Constitution, Content and Structure (New York: Palgrave Macmillan), 55-74.

MOORE, G.E. (1925) 'A Defence of Common Sense' in Moore (1959), 32-59

(1939) 'Proof of an External World' in Moore (1959), 127-150.

(1959) Philosophical Papers (London: George Unwin).Mounce, H. (2005)

MOUNCE, H.O. (2005) 'Wittgenstein and Classical Realism' in MoyalSharrock \& Brenner (2007), 103-121.

MOYAL-SHARROCK, D. (2007) Understanding Wittgenstein's On Certainty. Basingstoke, UK: Palgrave Macmillan.

(2013a) 'Realism, but not empiricism: Wittgenstein versus Searle' in The Role and Use of Conceptual Analysis in Psychology: A Wittgensteinian Perspective. Eds T. P. Racine and K. L. Slaney (Basingstoke, UK: Palgrave Macmillan)

(2013b) 'Wittgenstein's Razor: The Cutting Edge of Enactivism' American Philosophical Quarterly. 50:3 July 2013, 263-79.

PHILLIPS, D.Z. (1988) Faith After Foundationalism (London: Routledge).

STROLL, A.

(1994) Moore and Wittgenstein on Certainty. Oxford: Oxford University Press.

(2004) 'Wittgenstein's Foundational Metaphors' in The Third Wittgenstein: the post-Investigations works, ed. Moyal-Sharrock, D. (Aldershot, UK: Ashgate, 2004), 13-24.

TRAVIS, C. (1997) Pragmatics. In B. Hale and C. Wright (Eds). $A$ Companion to the Philosophy of Language (pp. 87-108). Oxford: Blackwell.

VON WRIGHT, G.H. (1982) Wittgenstein. Oxford: Basil Blackwell. 
WILLIAMS, M.

(1991) Unnatural Doubts: Epistemological Realism \& the Basis of Scepticism. Oxford: Blackwell.

(2001) Problems of Knowledge: A Critical Introduction to Epistemology Oxford: Oxford University Press.

(2004) 'Wittgenstein's Refutation of Idealism' in Wittgenstein and Scepticism (ed.) D. McManus (London: Routledge, 2004), 76-95.

(2005) 'Why Wittgenstein Isn't a Foundationalist' in Readings of Wittgenstein's On Certainty, eds. D. Moyal-Sharrock \& W. H. Brenner (Basingstoke: Palgrave Macmillan, 2005), 47-58.

WRIGHT, C. (1985) 'Facts \& Certainty' Proceedings of the British Academy, 429-72.

\section{Wittgenstein, L.}

AWL Wittgenstein's Lectures: Cambridge, 1932-1935, from the notes of A. Ambrose and M. MacDonald, ed. A. Ambrose. Oxford: Blackwell, 1979.

BT Big Typescript: TS 213. Oxford: Wiley-Blackwell, 2005.

CL Cambridge Letters: Correspondence with Russell, Keynes, Moore, Ramsey and Sraffa, ed. Brian McGuinness et G.H. von Wright. Oxford: Blackwell, 1985.

LW I Last Writings on the Philosophy of Psychology, vol I, ed. G.H. von Wright and H. Nyman, tr. C.G. Luckhardt and M.A.E. Aue. Oxford, Blackwell: 1982.

MWL Moore's Wittgenstein Lectures in 1930-1933 in Philosophical Occasions: 1912-1951, ed. J.C. Klagge and A. Nordman. (Indianapolis: Hackett Publishing, 1993) 46-114.

OC On Certainty, ed. G.E.M. Anscombe and G.H. von Wright, tr. D. Paul and G.E.M. Anscombe, amended 1st Edition. Oxford: Blackwell, 1977.

PG Philosophical Grammar, ed. R. Rhees, tr. A. Kenny. Oxford: Blackwell, 1974.

PI Philosophical Investigations, tr. G.E.M. Anscombe, 2nd Edition. Oxford: Blackwell, 1997 
RFM Remarks on the Foundations of Mathematics, ed. G.H. von Wright, R. Rhees and G.E.M. Anscombe, tr. G.E.M. Anscombe, 3rd revised Edition, Oxford: Blackwell, 1978.

Z Zettel. G.E.M. Anscombe and G.H. von Wright (eds), tr. G.E.M. Anscombe, Berkeley: University of California Press, 1970. 